Supporting Information

\title{
Designer Ionic Liquids for Reversible Electrochemical Deposition/Dissolution of Mg
}

\author{
Tylan Watkins, Ashok Kumar and Daniel A. Buttry* \\ School of Molecular Sciences, Arizona State University, Tempe, AZ, 85287-1604, USA \\ *Corresponding author email: Dan.Buttry@asu.edu
}

Tel: (480) 965-2476

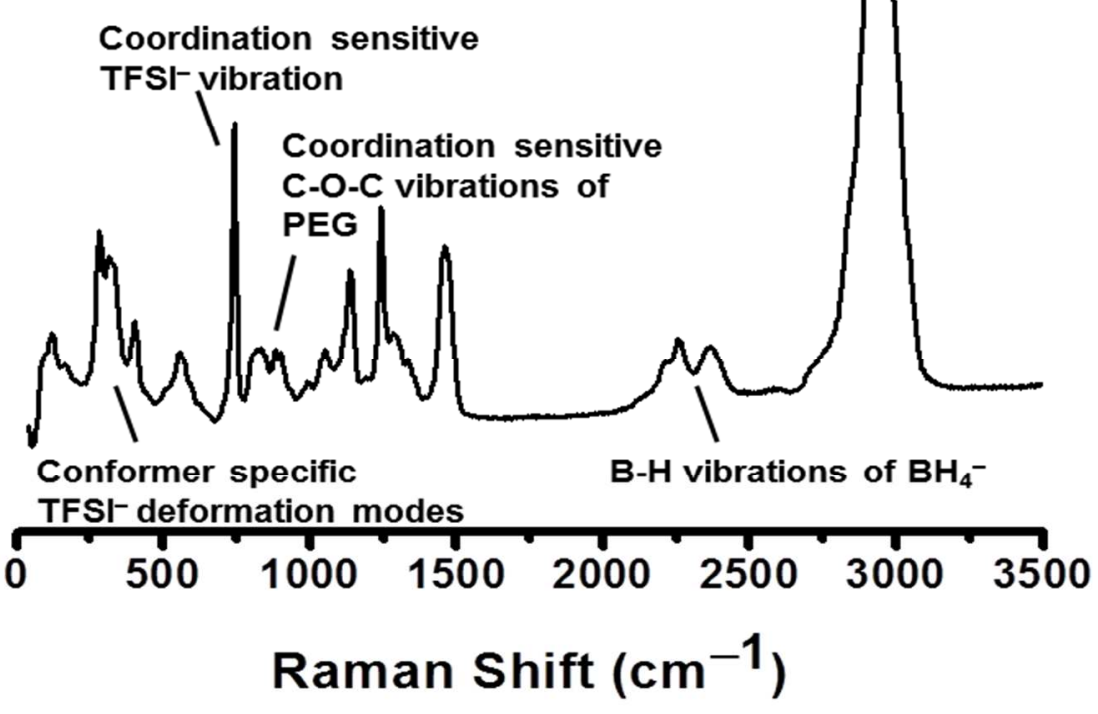

Figure S1: Raman spectrum (50-3800 $\left.\mathrm{cm}^{-1}\right)$ for electrolyte with composition $\left[\mathrm{Mg}\left(\mathrm{BH}_{4}\right)_{2}\right]_{0.3}\left[\mathrm{MPEG}_{7} \mathrm{PyrTFSI}_{0.7}\right.$. The four major regions of interest mentioned in the text are identified. 


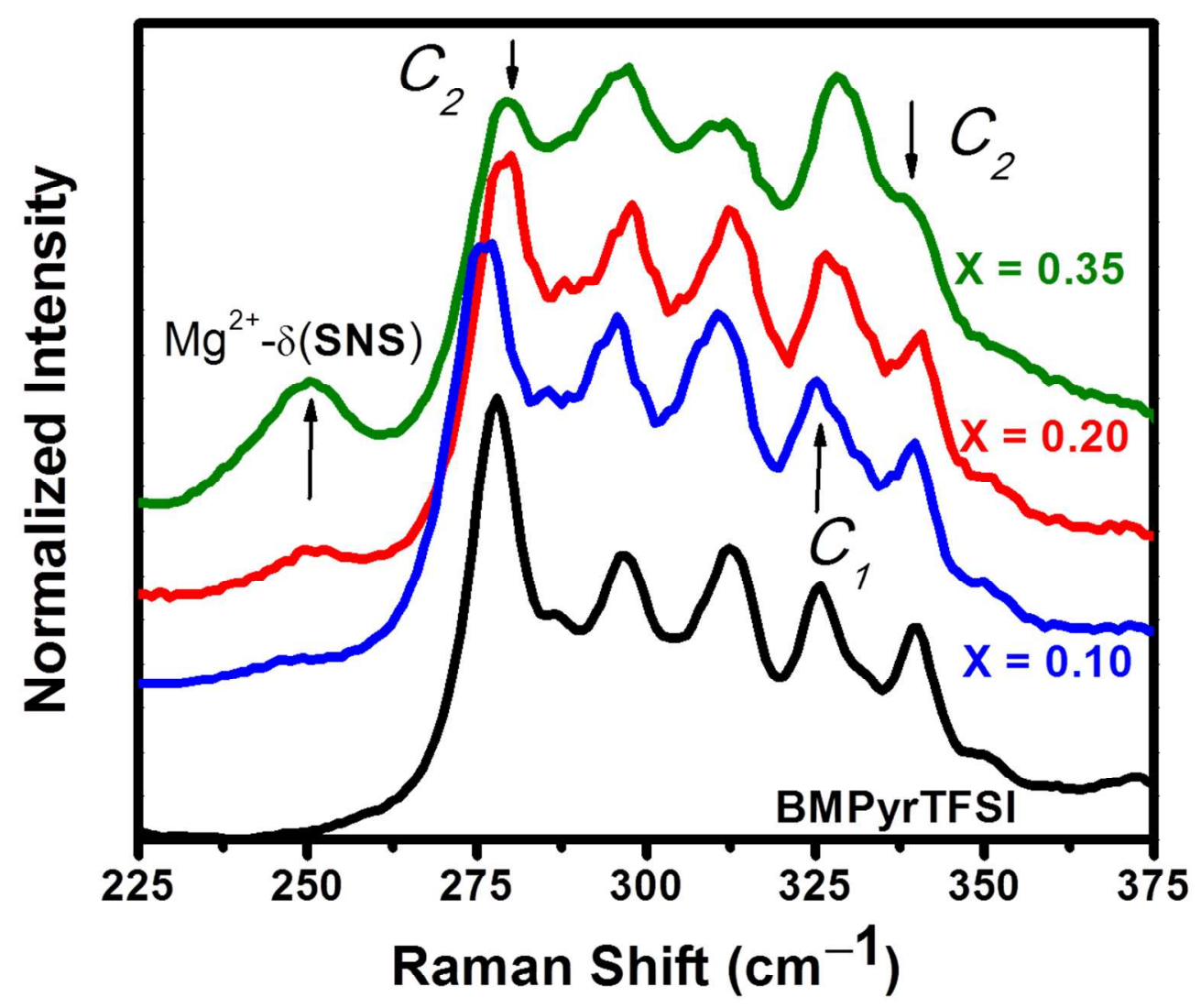

Figure S2: Conformational specific region for TFSI- modes at given $\mathrm{Mg}\left(\mathrm{BH}_{4}\right)_{2}$ mole fractions (x) in BMPyrTFSI, $\left[\mathrm{Mg}\left(\mathrm{BH}_{4}\right)_{2}\right]_{\mathrm{x}}[\mathrm{BMPyrTFSI}]_{1-\mathrm{x}}$. The cis $(\mathrm{Cl})$ conformer increases, while the trans $(\mathrm{C} 2)$ conformer decreases as the mole fraction of $\mathrm{Mg}\left(\mathrm{BH}_{4}\right)_{2}$ increases. This is consistent with previous reports for $\mathrm{Mg}^{2+}$ with $\mathrm{TFSI}^{-}$(references 26 and 31 in the main text). The mode at 250 also increases with an increase in $\mathrm{Mg}\left(\mathrm{BH}_{4}\right)_{2}$ and has been briefly described in references 26 and 32 . 


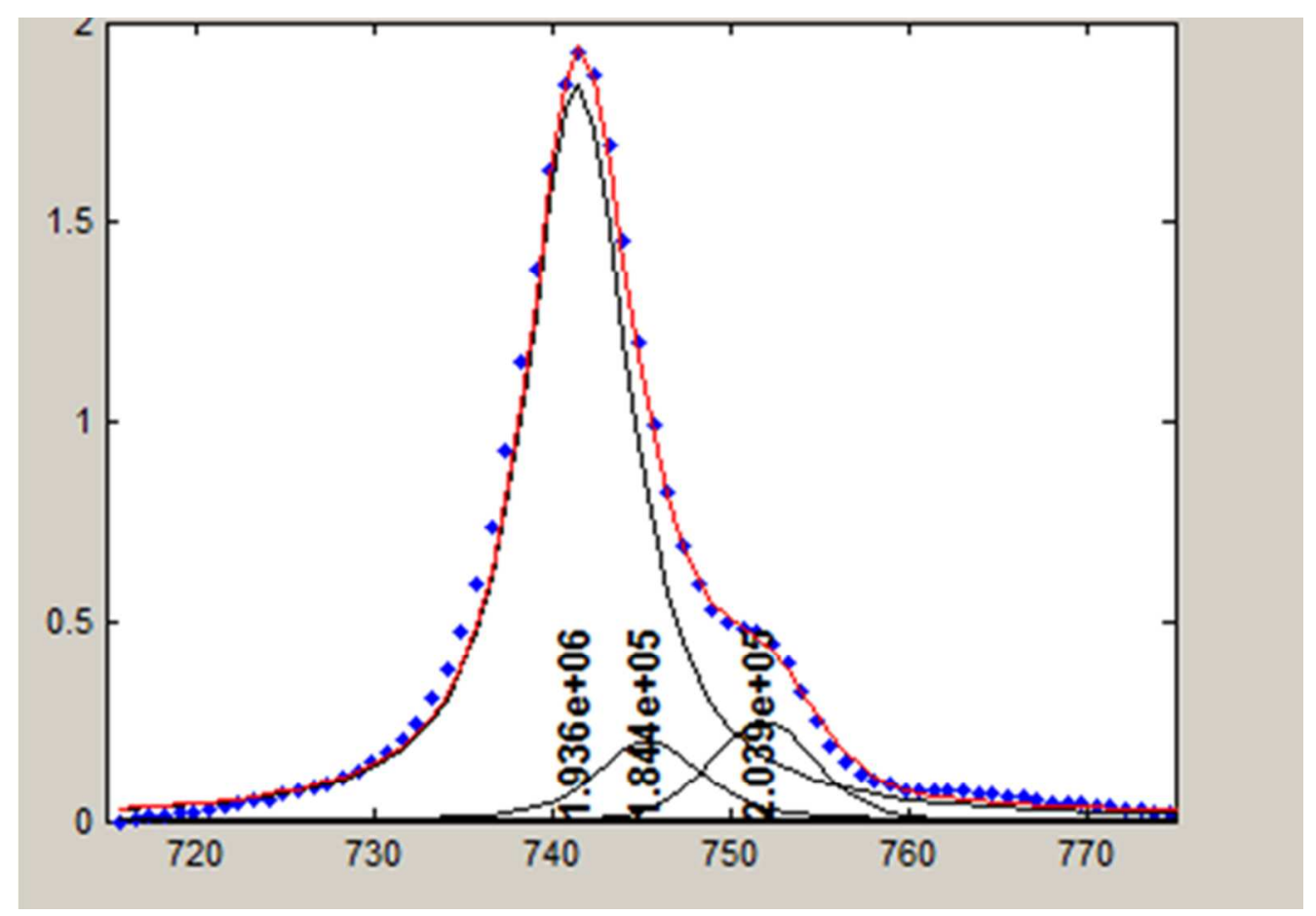

Figure S3: Example modeled fit for the coordination sensitive $\mathrm{TFSI}^{-}$peak in an electrolyte with composition $\left[\mathrm{Mg}\left(\mathrm{BH}_{4}\right)_{2}\right]_{0.15}[\mathrm{BMPyrTFSI}]_{0.85}$.
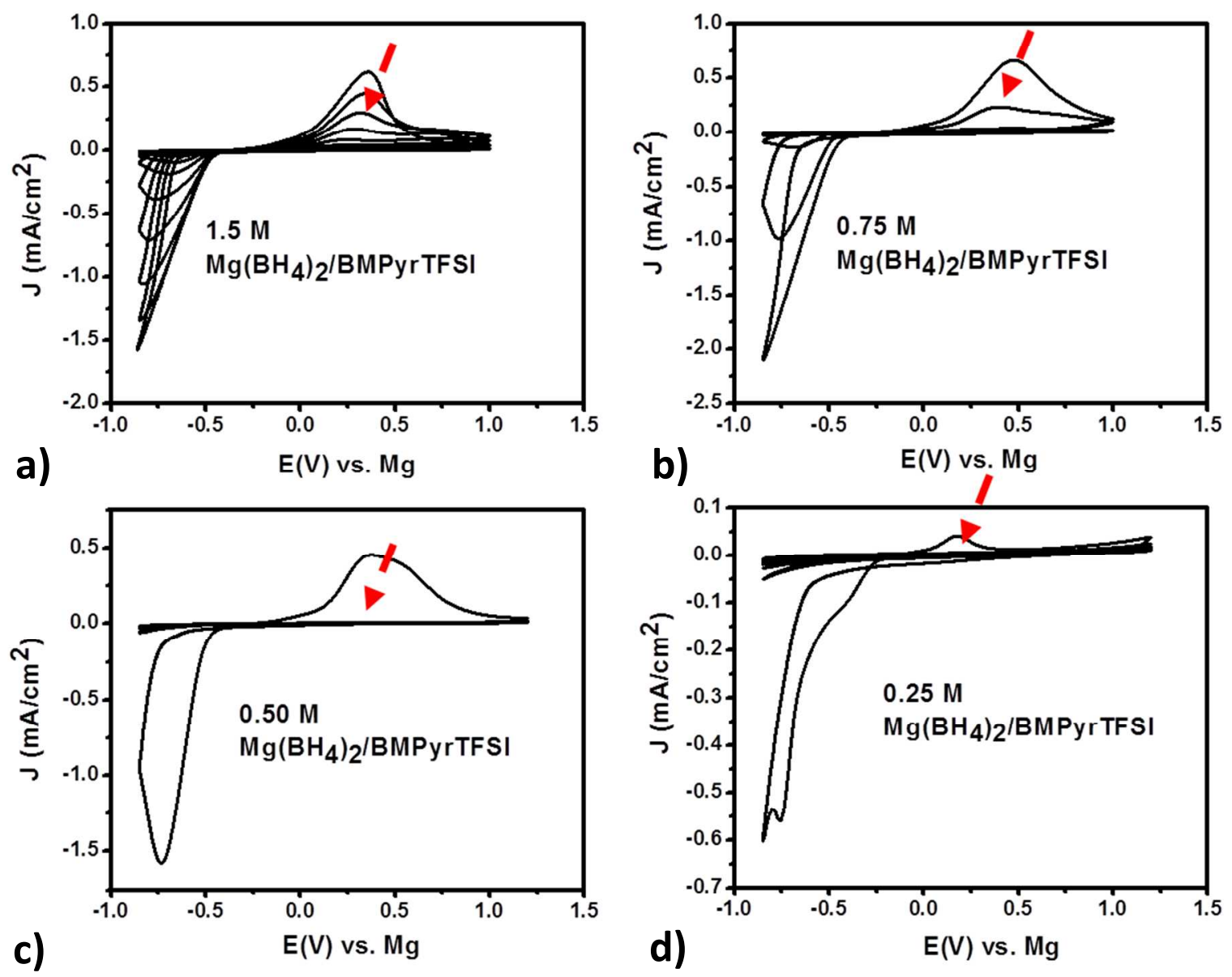

Figure S4: Successive CVs for $\mathrm{Mg}\left(\mathrm{BH}_{4}\right)_{2} / \mathrm{BMPyrTFSI}$ electrolytes at a) $1.5 \mathrm{M}$ b) $0.75 \mathrm{M} \mathrm{c}$ ) $0.50 \mathrm{M}$ and d) $0.25 \mathrm{M}$. 


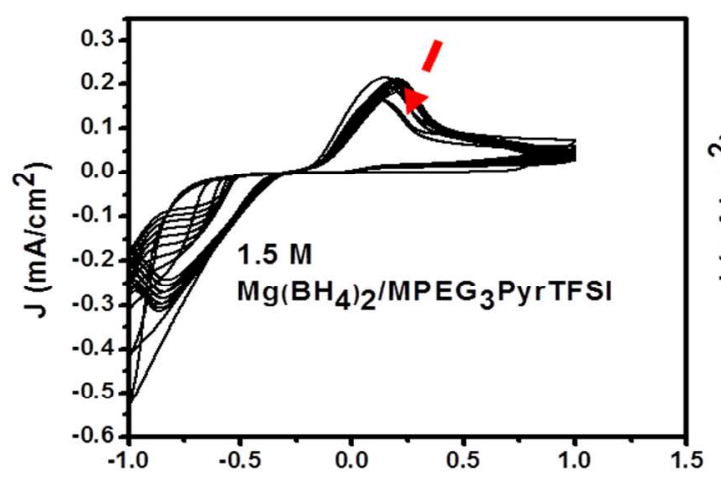

a)

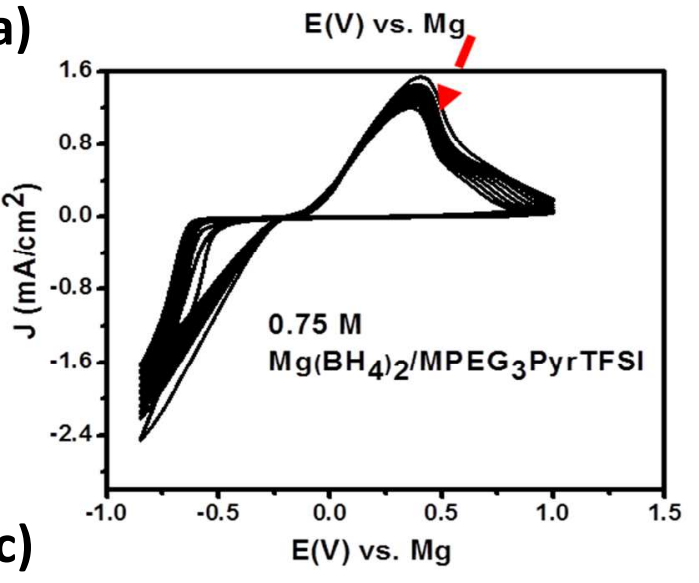

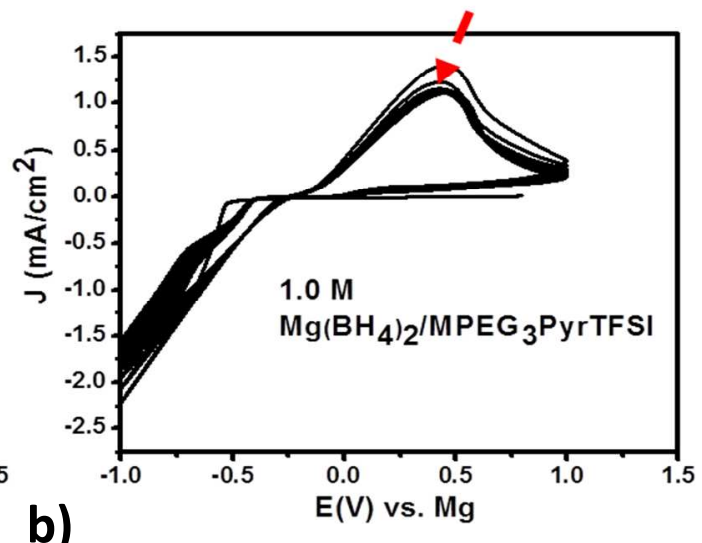

b)

$\mathrm{E}(\mathrm{V})$ vs. Mg
$1.0 \mathrm{M}$ $\mathrm{Mg}\left(\mathrm{BH}_{4}\right)_{2} / \mathrm{MPEG}_{3} \mathrm{PyrTFS}$

Figure S5: Successive $\mathrm{CVs}$ for $\mathrm{Mg}\left(\mathrm{BH}_{4}\right)_{2} / \mathrm{MPEG}_{3}$ PyrTFSI electrolytes at a) $1.5 \mathrm{M}$ b) $1.0 \mathrm{M}$ and c) $0.75 \mathrm{M}$
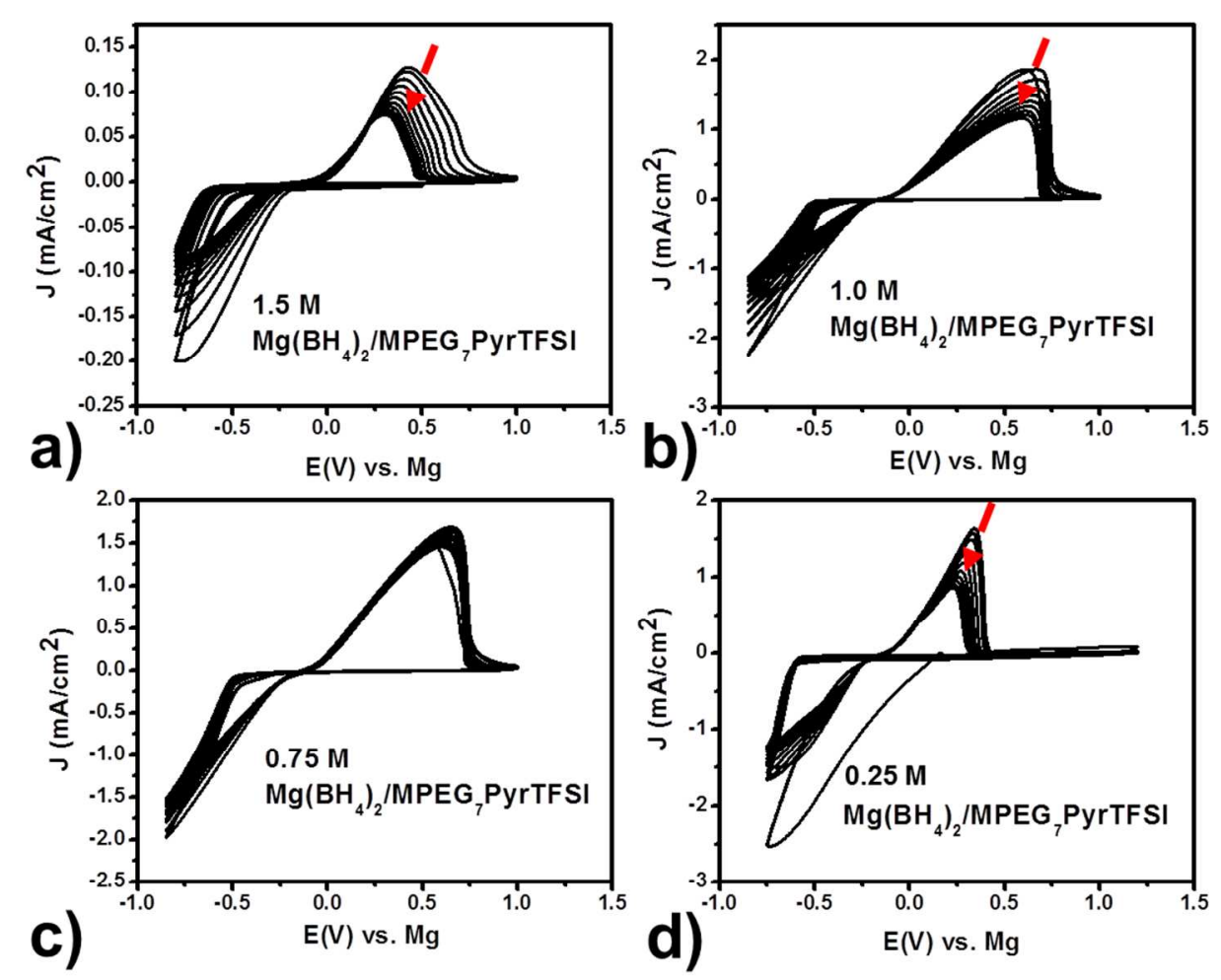

Figure S6: Successive $\mathrm{CVs}$ for $\mathrm{Mg}\left(\mathrm{BH}_{4}\right)_{2} / \mathrm{MPEG}_{7} \mathrm{PyrTFSI}$ electrolytes at a) $1.5 \mathrm{M}$ b) $1.0 \mathrm{M}$ c) $0.75 \mathrm{M}$ and d) $0.25 \mathrm{M}$. 


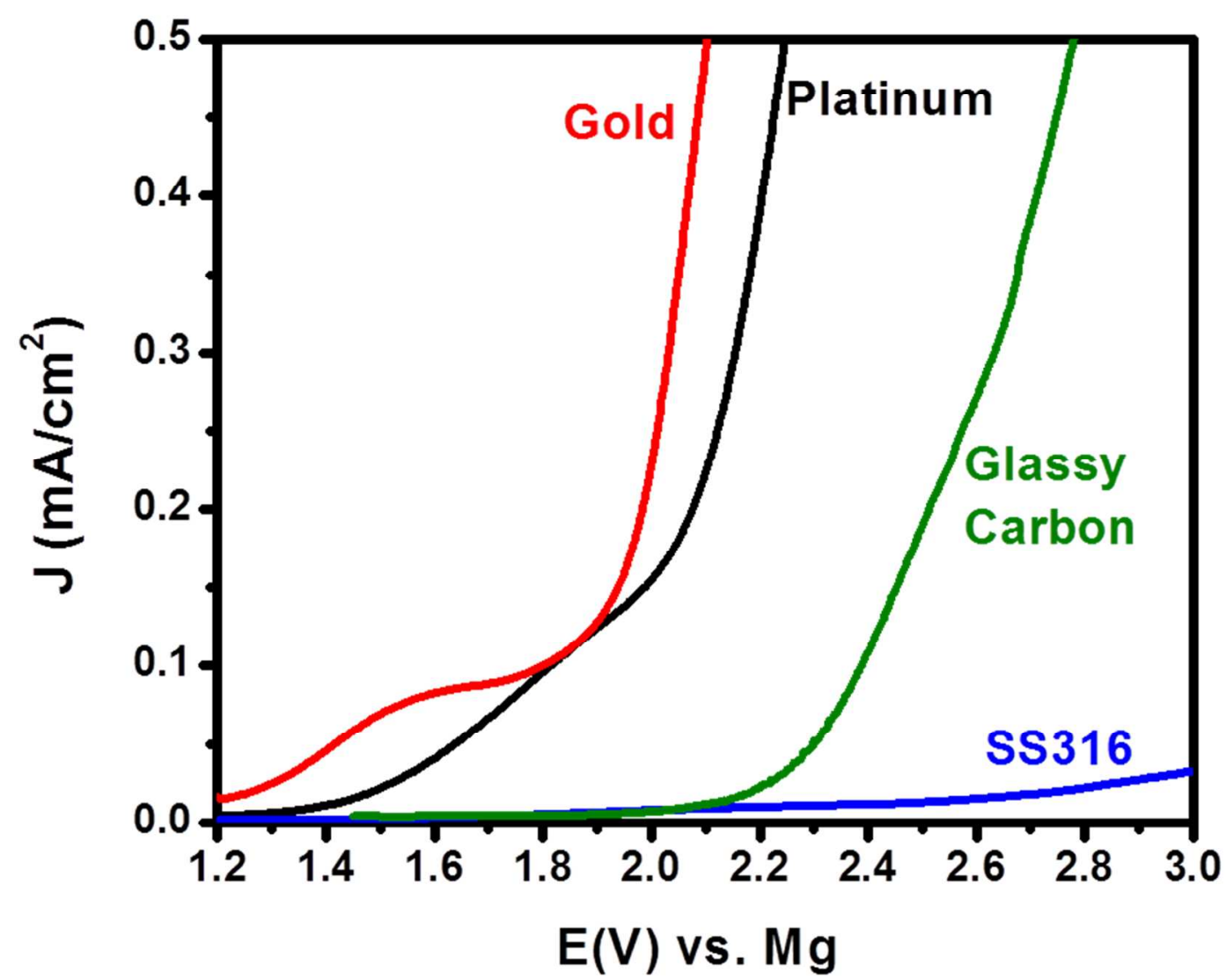

Figure S7: Linear sweep voltammograms for $0.5 \mathrm{M} \mathrm{Mg(BH4)2/MPEG7PyrTFSI.}$ The working electrodes are indicated in the figure, the reference and counter electrodes were polished $\mathrm{Mg}$ and the scan rate was $1 \mathrm{mV} / \mathrm{s}$. Note: a two electrode set-up was used for the stainless steel (SS316) measurement.

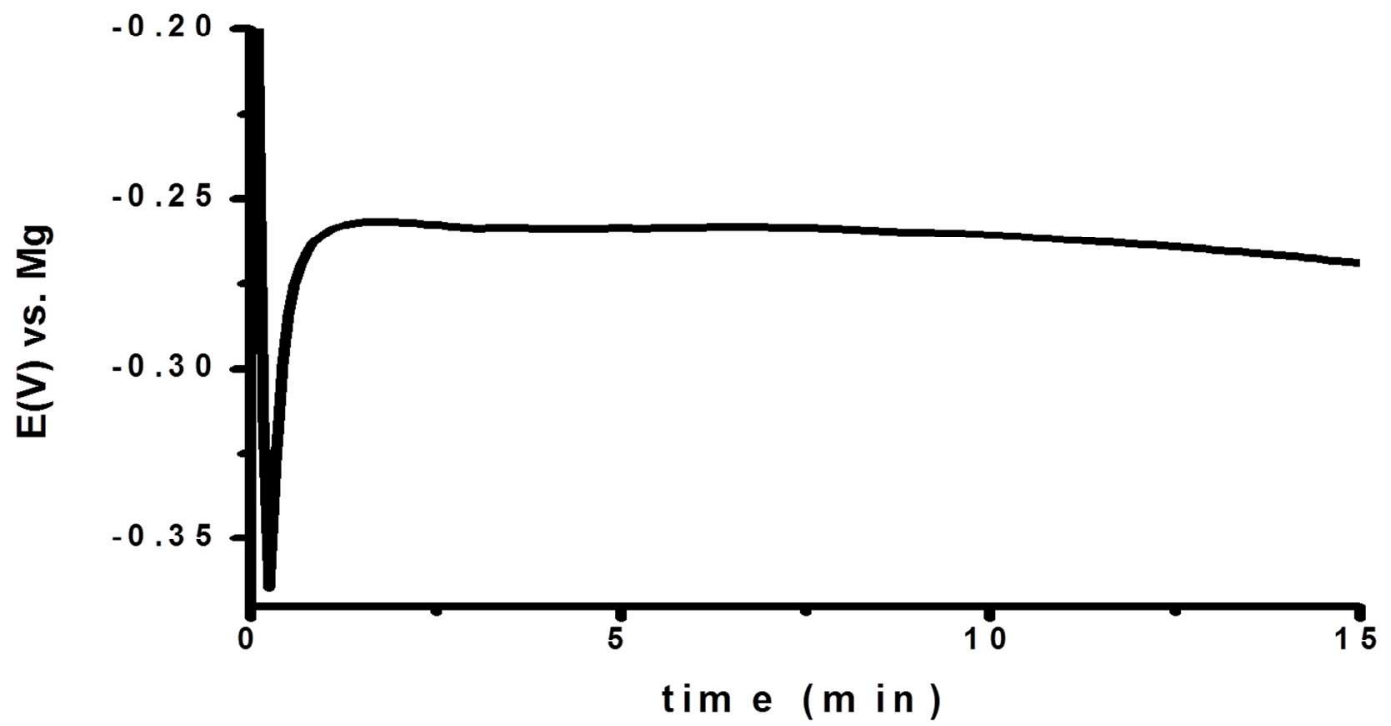

Figure S8: Potential trace (first 15 minutes) for $0.1 \mathrm{~mA} / \mathrm{cm}^{2}$ galvanostatic deposition of $\mathrm{Mg}$ on $\mathrm{Au}$ in $0.5 \mathrm{M} \mathrm{Mg}\left(\mathrm{BH}_{4}\right)_{2} / \mathrm{MPEG}_{7}$ PyrTFSI. 


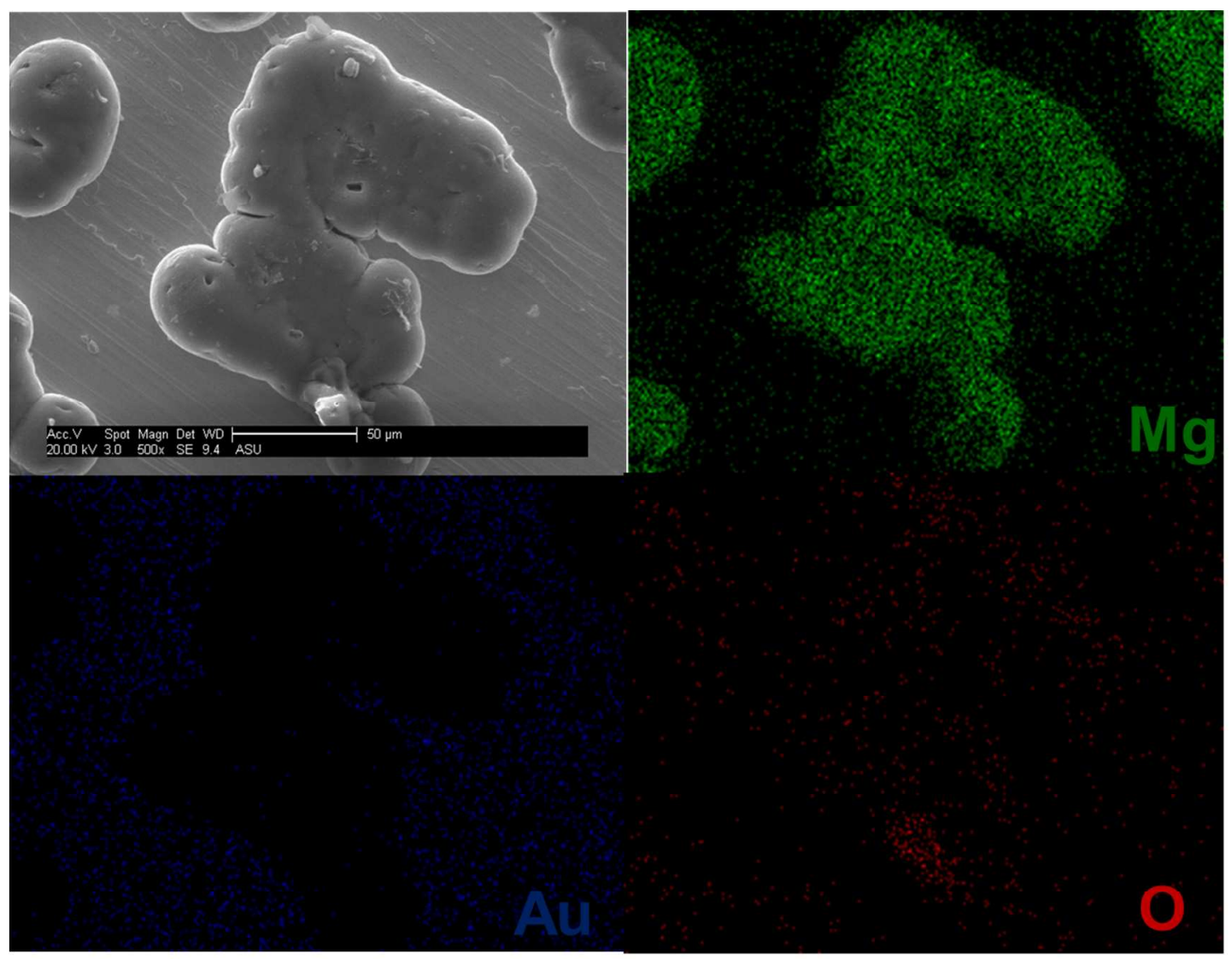

Figure S9: EDS elemental mapping for the area in figure $10 \mathrm{~b}$.

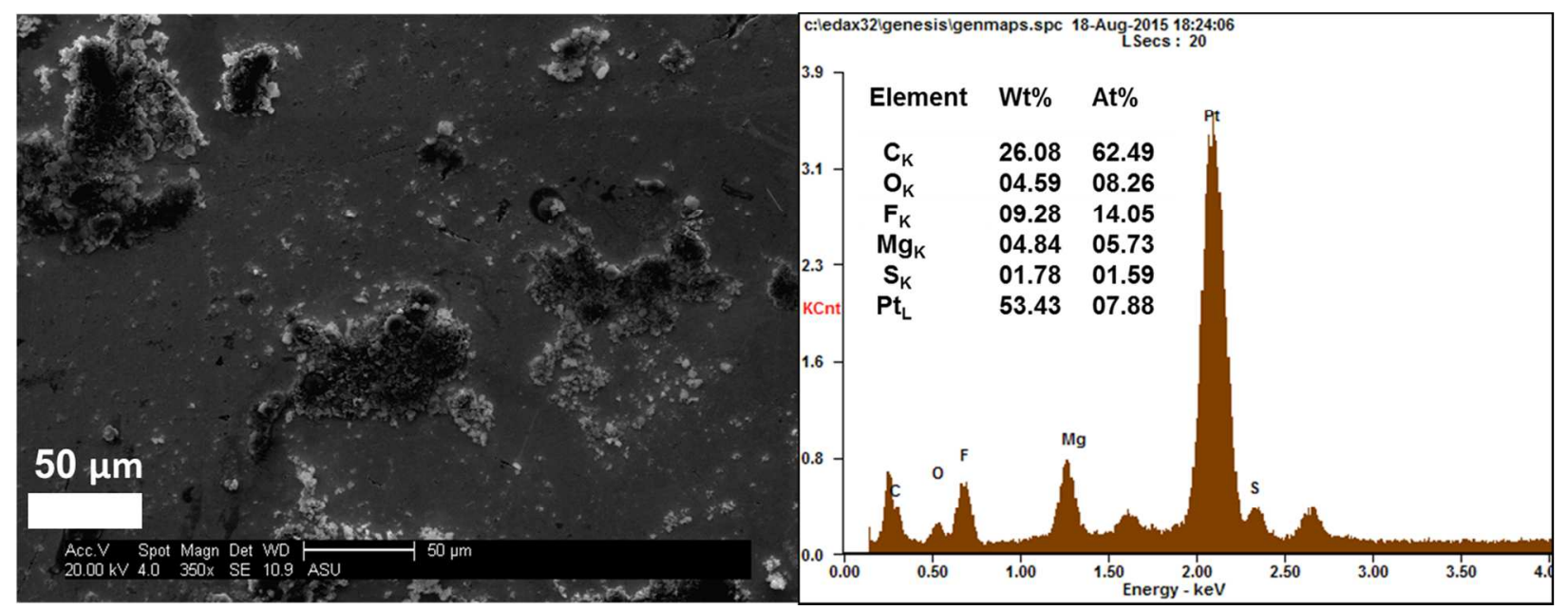

Figure S10: SEM image (left) and EDS spectrum (right) for $0.1 \mathrm{~mA} / \mathrm{cm}^{2}$ deposition from $0.75 \mathrm{M}$ $\mathrm{Mg}\left(\mathrm{BH}_{4}\right)_{2} / \mathrm{BMPyrTFSI}$. 


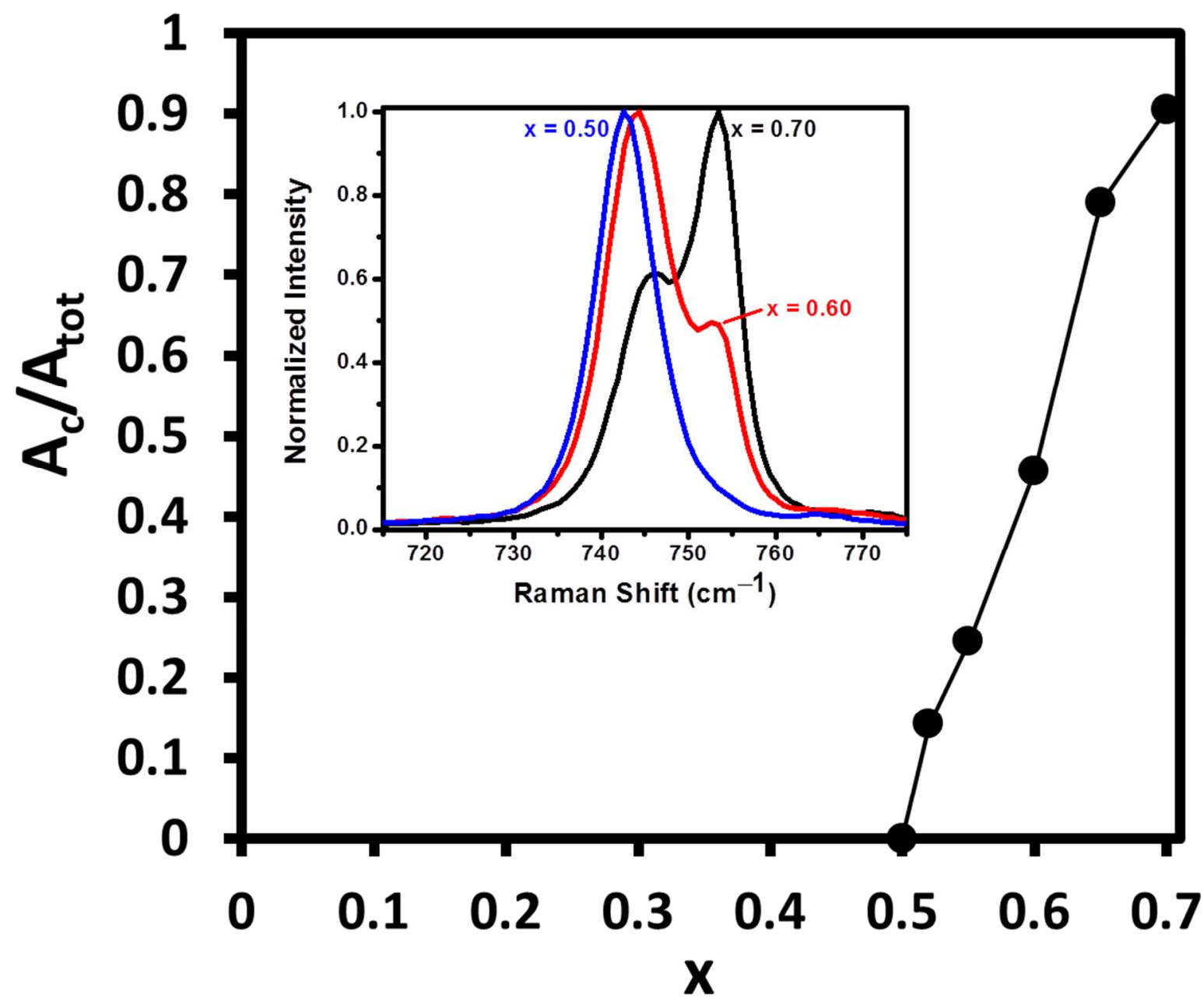

Figure S11: Fraction of coordinated $\mathrm{TFSI}^{-}\left(\mathrm{A}_{\mathrm{c}} / \mathrm{A}_{\text {tot }}\right)$ vs. molar fraction of $\mathrm{Mg}(\mathrm{TFSI})_{2}(\mathrm{x})$ for the $\left[\mathrm{Mg}(\mathrm{TFSI})_{2}\right]_{\mathrm{x}}\left[\mathrm{MPEG}_{7} \mathrm{PyrTFSI}_{1-\mathrm{x}}\right.$ system. Inset shows the raw spectra for $\mathrm{x}=0.50$ (blue), $\mathrm{x}=$ 0.60 (red), and $\mathrm{x}=0.70$ (black). 


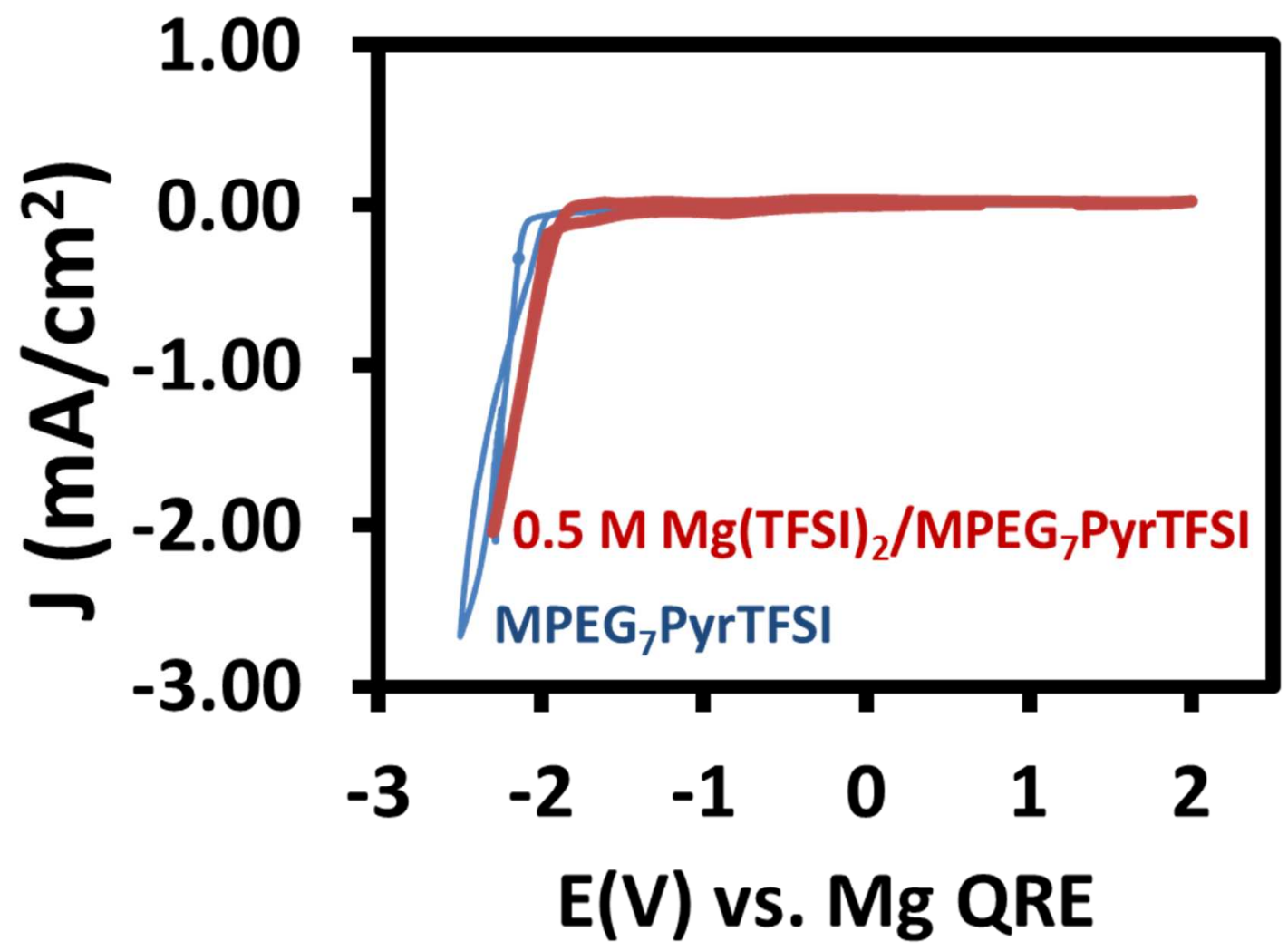

Figure S12: $\mathrm{CV}$ s of the $\mathrm{MPEG}_{7}$ PyrTFSI IL (blue) and a $0.5 \mathrm{M} \mathrm{Mg}(\mathrm{TFSI})_{2} / \mathrm{MPEG}_{7} \mathrm{PyrTFSI}$ solution (red).

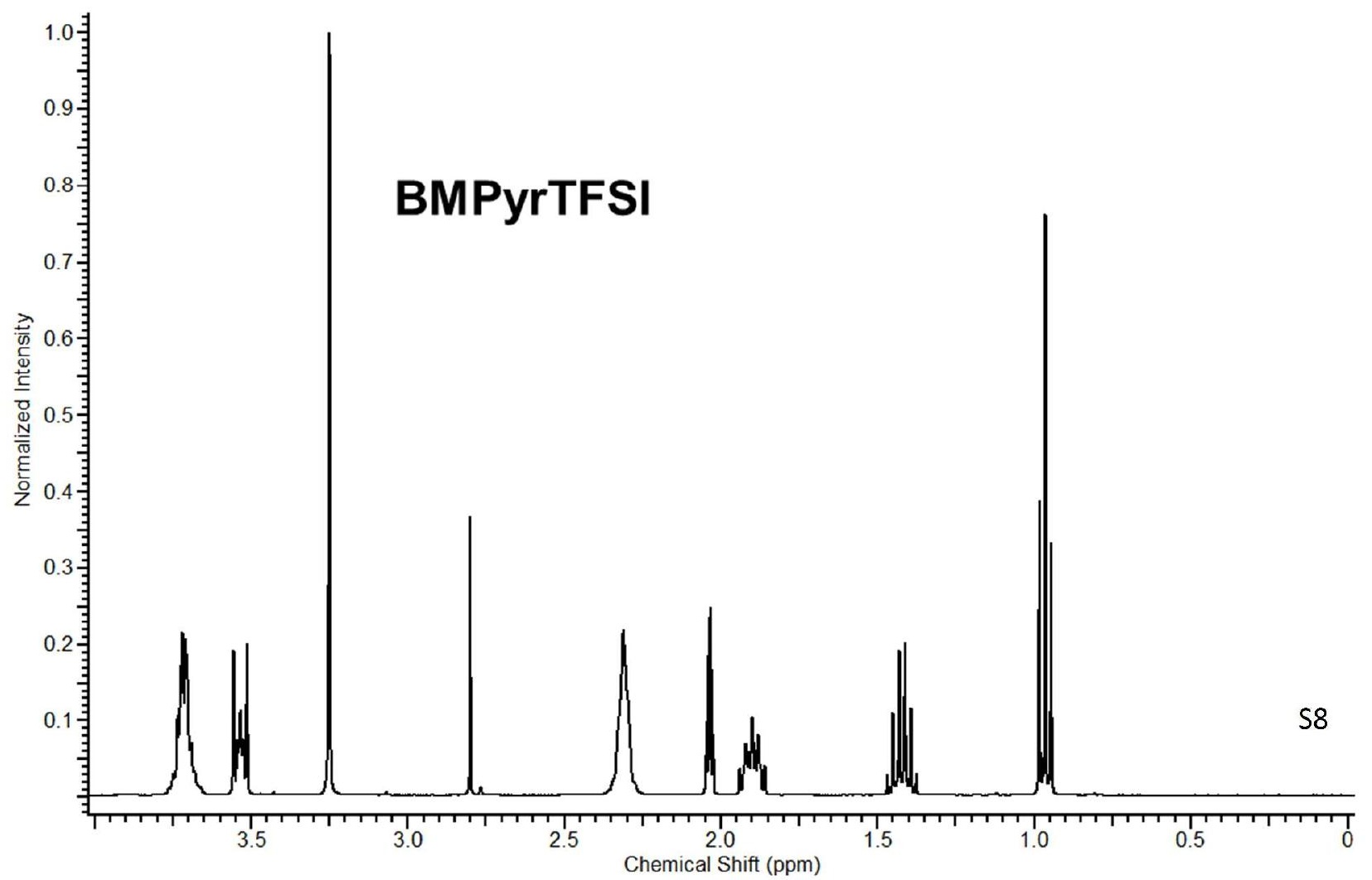



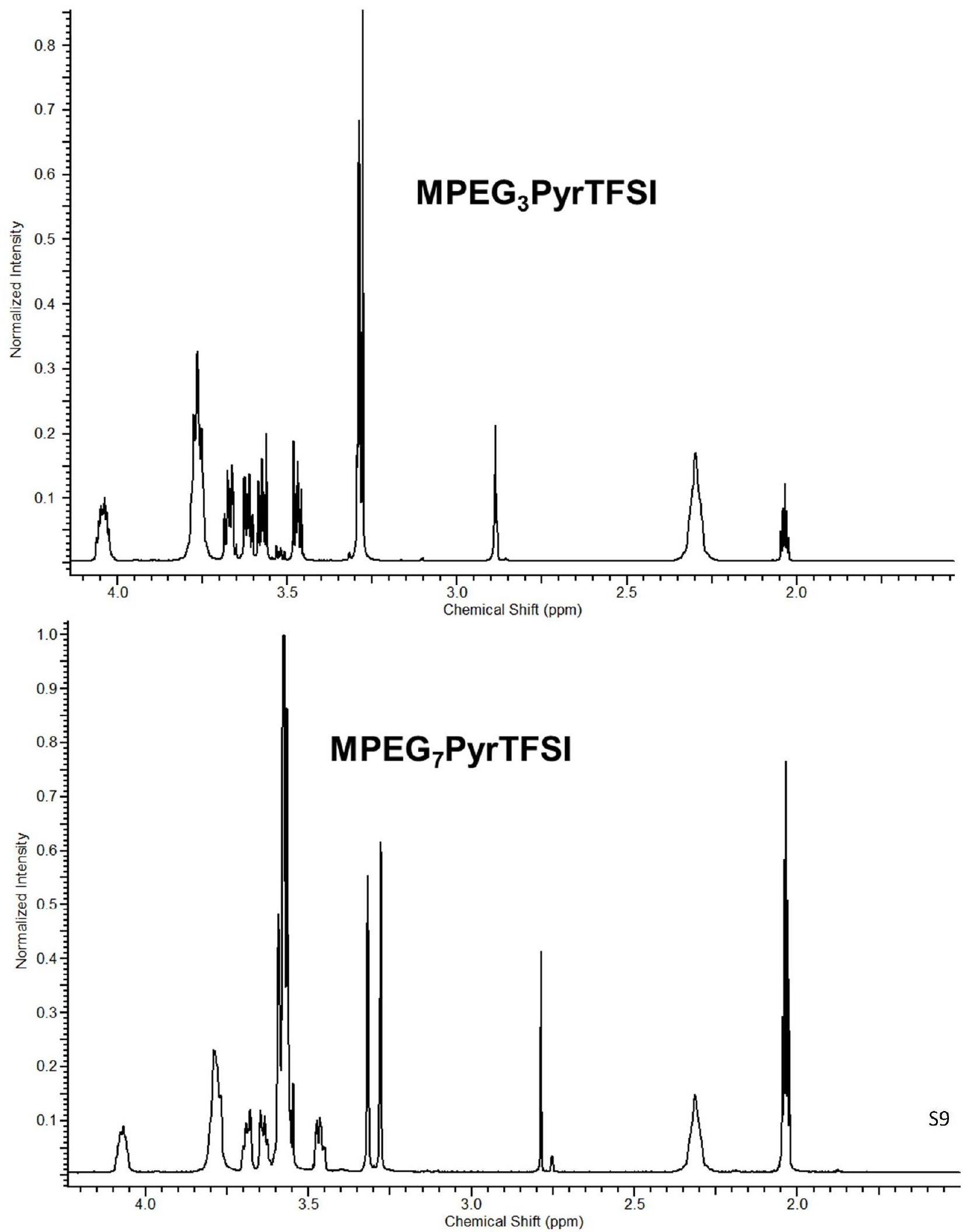